\title{
Anxiety Symptomatology and Patterns of Coping amongst Medical Doctors and Nurses in Nigeria during the COVID-19 Pandemic: An Online Cross-Sectional Survey
}

\author{
Seb-Akahomen Omonefe $\mathrm{J}^{1 *}$, Okogbenin Esther ${ }^{1,2}$, Obagaye Olukunle $\mathrm{M}^{1}$, Erohubie \\ Paul $O^{1}$ and Aweh Benjamin $E^{1}$
}

${ }^{1}$ Consultant Psychiatrist, Department of Psychiatry, Irrua Specialist Teaching Hospital, Nigeria

${ }^{2}$ Associate Professor of Psychiatry, Department of Psychiatry, Ambrose Alli University, Nigeria

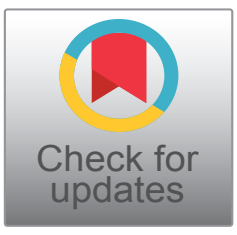

*Corresponding author: Dr. Seb-Akahomen Omonefe J, Consultant Psychiatrist, Department of Psychiatry, Irrua Specialist Teaching Hospital, P.M.B. 08, Irrua, Edo state, Nigeria, Tel: +2348037575629

\begin{abstract}
Background: The unprecedented global crisis triggered by the COVID-19 pandemic led to a cascade of overwhelming pressure on the healthcare system. Frontline healthcare professionals (HCPs), especially doctors and nurses were confronted with an increased risk of mental disorders, most commonly identified are anxiety disorders. This study aimed to determine the prevalence of anxiety symptomatology amongst doctors and nurses in Nigeria and the effects of the coping pattern of participants on the symptoms of anxiety.

Methods: This was an online cross-sectional survey conducted between April and July 2020. A total of 464 physicians and nurses participated in the study. Anxiety was measured using the 7-item Generalized Anxiety Disorders (GAD-7) questionnaire. Coping patterns or methods were assessed with questions derived from the $\mathrm{WHO}$ resource on managing Mental Health during the COVID-19 Pandemic, including other adaptive and maladaptive coping strategies.

Results: Overall, $39.9 \%$ of participants reported experiencing anxiety, with varying levels of severity. While $12 \%$ of participants were diagnosed with moderate to severe levels of GAD. Multivariate analysis revealed that female gender (AOR: 3.82; 95\% Cl: 1.68-8.68), fewer years of work experience (AOR: $1.10 ; 95 \% \mathrm{Cl}$ : 1.02-1.18) and a lifetime history of psychological illness (AOR: 3.28; 95\% $\mathrm{Cl}$ : 1.15-9.34), independently increased the odds of GAD, while adopting healthy lifestyle modifications (AOR: 0.49; $95 \% \mathrm{Cl} ; 0.28-1.00)$ and spending time with close relatives (AOR $0.47 ; 95 \% \mathrm{Cl}: 0.26-0.93$ ), independently reduced the odds of GAD.
\end{abstract}

Conclusion: The study findings revealed a substantial rate of GAD, among physicians and nurses during the early phase of the COVID-19 pandemic in Nigeria. Proactive measures are required to prevent mental health problems such as anxiety disorders in HCPs.

\section{Keywords}

Anxiety symptomatology, COVID-19, Healthcare professionals, Nigeria

\begin{abstract}
Abbreviations
WHO: World Health Organization; COVID-19: Coronavirus Disease 2019; HCPs: Health Care Professionals; SARS: Severe Acute Respiratory Syndrome; GAD: Generalized Anxiety Disorder
\end{abstract}

\section{Introduction}

\section{Background of the study}

According to the World Health Organization (WHO), the outbreak of a new coronavirus disease 2019 (COVID-19) is a Public Health Emergency of International Concern [1]. Subsequently, with evidence of a rising global incidence in the rates of the COVID-19 outbreak, the WHO declared that COVID-19 can be characterized as a pandemic [1]. Truly, the coronavirus pandemic is this century's most urgent challenge to humanity [2].

Citation: Seb-Akahomen OJ, Okogbenin EO, Obagaye OM, Erohubie PO, Aweh BE (2021) Anxiety Symptomatology and Patterns of Coping amongst Medical Doctors and Nurses in Nigeria during the COVID-19 Pandemic: An Online Cross-Sectional Survey. Int J Depress Anxiety 4:028. doi. org/10.23937/2643-4059/1710028

Accepted: December 29, 2021: Published: December 31, 2021

Copyright: (C) 2021 Seb-Akahomen OJ, et al. This is an open-access article distributed under the terms of the Creative Commons Attribution License, which permits unrestricted use, distribution, and reproduction in any medium, provided the original author and source are credited. 
This period of catastrophe has led to pressure and panic all over the population, especially for health care personnel who as a result of the paradigm shift in the globe, find themselves in the frontlines against the new coronavirus. At the core of the unparalleled crisis of COVID-19, HCPs face several challenges; many are suddenly encumbered with profound tasks, such as treating patients with COVID-19: Reducing the spread of infection; developing suitable short-term strategies; and formulating long-term plans [3]. These may be aggravated by a greater risk of infection and death they never envisaged at this time of their lives [2]. The WHO describes the COVID-19 outbreak as a unique and unprecedented scenario for many health workers, particularly if they have not been involved in similar responses [1]. Also, there have been reports of situations in which some doctors and nurses, unfortunately, experience avoidance by their family or community owing to stigma or fear [1,4], this can make an already challenging situation far more difficult. These factors coupled with working long hours, limited safety equipment and witnessing the traumatic course of the infection and their patients' death are likely to lead to psychological distress and precipitate mental illnesses such as anxiety symptoms and/or disorders amongst these individuals.

There is research evidence that demonstrates the outbreak of a coronavirus which is clinically and epidemiological similar to COVID-19, the Severe Acute Respiratory Syndrome (SARS) [5-7]. The SARS epidemic was characterized by significant episodes of mental health morbidities among health care workers [57]. In the same vein, with the emergence of the new coronavirus pandemic, there has been demonstrable evidence of psychological morbidities among health workers who work in the frontlines, one of such major mental health morbidity are anxiety disorders [8-10]. Poor mental health outcomes such as anxiety often connote a poorer quality of life and a decline in functioning for the affected health care workers.

Health care professionals (HCPs), nurses and medical doctors have been recognized as having a high risk of psychological illnesses in relation to the ongoing pandemic $[8,11,12]$. Recent findings especially from systematic reviews and meta-analysis, demonstrate that nurses are particularly more likely to experience anxiety as a result of the pandemic compared to other HCPs $[12,13]$. Some factors such as having closer contact with infected patients, greater risk of infection, as well as work pressure, may account for this. Furthermore, anxiety symptoms have been recognized as the commonest psychological morbidity amongst healthcare personnel during the ongoing COVID-19 pandemic $[11,12]$. Also, anxiety disorders and other mental illnesses, place a huge burden on the functioning of health care workers and may invariably determine the health outcomes of the patients and the efficiency of the health care system in general. The psychological burden on HCPs triggered by the pandemic has received intense awareness in research publications $[14,15]$. However, there is a paucity of evidence on how coping patterns affect mental health outcomes in general.

To the best of our knowledge, no research has been conducted on the prevalence of anxiety symptomatology and the coping patterns of health care professionals (specifically, doctors and nurses) in Nigeria during the COVID-19 pandemic, hence the need for this study. We hope to utilize the information from this research to develop interventions and recommendations which would improve the mental health of doctors and nurses during distressing times.

\section{Objective of the study}

This study aimed to determine the prevalence of anxiety symptomatology amongst doctors and nurses in Nigeria and the effects of the coping pattern of the participants on the symptoms of anxiety.

\section{Methodology}

\section{Setting and design}

This is a cross-sectional online survey of doctors and nurses in Nigeria.

\section{Participants}

Included in the study were, consenting medical doctors and nurses who practice in both public and private health care institutions in Nigeria. All Medical doctors and nurses in Nigeria, who refuse to give consent were excluded from the study.

\section{Sample size}

In a study conducted by Laiet, et al. the prevalence of anxiety symptoms in a population of health care workersduring the COVID-19 pandemic was found to be $44.6 \%$ [8].

Using the sample size estimation formula for single proportions [16],

$N=\frac{Z^{2} p q}{d^{2}}$

Where $\mathrm{N}=$ sample size

$Z=1.96$ (95\% confidence interval)

$p=$ Estimated prevalence of the variable

$q=1-p$,

$\mathrm{d}=$ degree of accuracy desired, set at 0.05

Values of $Z=1.96, p=0.446, q=0.554, d=0.05$

$N=\frac{1.96^{2} \times 0.446 \times 0.554}{0.05^{2}}$

$=379.68$ 
To allow for attrition, $10 \%$ of the calculated sample size is added;

$379.68+37.97=417.65$

Minimum sample size $=\sim 418$

A total of 464 participants however completed the online survey.

\section{Data collection}

Participants were interviewed through online platforms for doctors and nurses in Nigeria, using semistructured and structured questionnaires incorporating socio-demographics, basic clinical history, mental wellbeing assessment, and an assessment of depression. The recruitment of participants spanned between April and July 2020.

\section{Measures}

The socio-demographic/clinical history questionnaire: This was designed to provide information about the respondent's age, gender, marital status, occupation, the highest level of formal education. Clinical variables such asthe presence of an underlying medical condition and a previous history of mental illness were ascertained as well.

The generalized anxiety disorder-7 (GAD-7): Is a 7-item self-report questionnaire that allows for the rapid detection of GAD [17]. Participants are asked if they were bothered by anxiety-related problems over the past two weeks by answering seven items on a 4-point scale. The total scores range from 0 to 21 . At a cutoff score of 10 , the GAD-7 had a sensitivity of $89 \%$ and a specificity of $82 \%$ for detecting GAD compared with a structured psychiatric interview [17]. Notably, among clinical and general population samples, the GAD-7 has demonstrated good reliability and crosscultural validity as a measure of GAD [17]. A score of 10 or greater on the GAD-7 represents a reasonable cut point for identifying cases of GAD. Regarding severity, cut points of 5-9, 10-14, and 15-21 are interpreted as representing mild, moderate, and severe levels of anxiety on the GAD-7, similar to levels of depression on the PHQ-9 [17].

Assessment of coping strategies: Participants were asked how they have coped so far with the COVID-19 pandemic. Possible options were derived from the WHO resources on managing Mental Health during the COVID-19 Pandemic, including other adaptive and maladaptive coping strategies $[1,18,19]$. Checkboxes were made available for participants to tick as many options as apply to them. Participants could also specifically indicate any other method(s) of coping that are not listed amongst the options. Examples of the assessments on coping include: maintaining a healthy lifestyle, spending time with loved ones whom you live with if feasible, getting social support from colleagues or seniors, internet use, keeping up-to-date with scientific updates on COVID-19, maintaining communication with loved ones who are faraway (e.g., phone calls, social media chats), getting enough rest between work hours/ shifts and religion. Others include the use of alcohol or other psychoactive substances to deal with the stress and taking out the stress or anxiety on colleagues and loved ones.

\section{Ethical considerations}

Ethical clearance was obtained from the Irrua Specialist Teaching Hospital's research and ethical committee. Informed consent was obtained from each participant. Confidentiality and anonymity were ensured by excluding the names of the participants on the questionnaire, emails of participants were not collected as well. The participants were assured that their participation is entirely voluntary.

\section{Statistical analysis}

The data were analysed using the Statistical Package for Social Sciences (SPSS) version 21. Descriptive statistics were used to summarise socio-demographic and clinical related data. Participants were classified as cases or noncases of anxiety disorders, based on a GAD-7 cut-off of 10 and above. Bivariate analyses were conducted using Chi-square, to identify socio-demographic and clinical factors associated with anxiety. Fisher's exact test was used for cells with expected frequencies $<5$. The scores of the Likert scale were also analyzed as continuous variables for the student's $\mathrm{t}$-test.Also a P-value of $<0.05$ was considered statistically significant.

For bivariate and multivariate analysis a score of 10 or greater on the GAD-7 (which represents a reasonable cutoff point for identifying 'cases' of anxiety disorders), was used to dichotomize participants into two groups ("Yes" or "No"). Also, marital status was grouped into "Single/separated/divorced/widowed" and "married/ cohabiting". Furthermore, a binary logistic regression model was utilized for the multivariate analysis. anxiety was the dependent variable, the model also included explanatory variables such as; age, years of experience, gender, marital status, occupation, having a friend or loved one infected with COVID-19, having personally been infected with COVID-19, previous history of psychological illness, coping with healthy diets/ exercise and spending time with relatives (if feasible). Independent variables were entered into the model using the forced entry method.

\section{Results}

\section{Socio-demographic and clinical characteristics of participants}

Table 1 shows the distribution of the sociodemographic characteristics of the study participants. Two hundred and twenty-five (48.5\%) participants were 
Table 1: Socio-demographic characteristics of participants.

\begin{tabular}{|c|c|c|c|}
\hline Variable & Frequency $(\mathrm{N}=464)$ & Percentage (\%) & Descriptive statistics \\
\hline \multicolumn{4}{|l|}{ Age (years): } \\
\hline $21-30$ & 61 & 13.1 & \multirow{4}{*}{$\begin{array}{l}\text { Mean }( \pm S D)=39.85( \pm 8.49) \\
\text { Range: } 21-63\end{array}$} \\
\hline $31-40$ & 225 & 48.5 & \\
\hline $41-50$ & 118 & 25.4 & \\
\hline $51-63$ & 60 & 12.9 & \\
\hline \multicolumn{4}{|l|}{ Gender: } \\
\hline Male & 189 & 40.7 & \\
\hline Female & 275 & 59.3 & \\
\hline \multicolumn{4}{|l|}{ Living status: } \\
\hline Living alone & 67 & 14.4 & \\
\hline Living with another adult(s) & 66 & 14.2 & \\
\hline Living with children and another adult(s) & 286 & 61.6 & \\
\hline $\begin{array}{l}\text { Living with children, elderly person(s) and/or } \\
\text { person(s) with a chronic medical condition }\end{array}$ & 45 & 9.7 & \\
\hline \multicolumn{4}{|l|}{ Marital status: } \\
\hline Single/Never married & 88 & 18.9 & \\
\hline Married & 354 & 76.3 & \\
\hline Cohabiting & 1 & 0.2 & \\
\hline Divorced & 3 & 0.7 & \\
\hline Widowed & 11 & 2.4 & \\
\hline Separated & 7 & 1.5 & \\
\hline \multicolumn{4}{|l|}{ Occupation: } \\
\hline Medical doctor & 296 & 63.8 & \\
\hline Nurse & 168 & 36.2 & \\
\hline \multicolumn{4}{|l|}{ Years of practice: } \\
\hline $1-5$ & 106 & 22.8 & \multirow[t]{5}{*}{ Mean $( \pm S D)=12.36( \pm 8.47)$} \\
\hline $6-10$ & 126 & 27.2 & \\
\hline $11-15$ & 113 & 24.4 & \\
\hline $16-20$ & 53 & 11.4 & \\
\hline $21-39$ & 66 & 14.2 & \\
\hline \multicolumn{4}{|l|}{ Employer: } \\
\hline Government & 393 & 84.7 & \\
\hline Private & 71 & 15.3 & \\
\hline \multicolumn{4}{|c|}{ The number of participants by geopolitical zones in Nigeria: } \\
\hline South-South & 295 & 63.6 & \\
\hline South-West & 82 & 17.7 & \\
\hline South-East & 11 & 2.4 & \\
\hline North-Central & 45 & 9.7 & \\
\hline North-West & 26 & 5.6 & \\
\hline North-East & 5 & 1.1 & \\
\hline
\end{tabular}

in the 31-40 years age group. The mean age ( \pm SD) of the participants was $39.85( \pm 8.49)$ years, with their ages ranging between 21 to 63 years. Two hundred and seventy-five participants $(59.3 \%)$ were female, over two-thirds of the participants were married $(n=$ $354 ; 76.3 \%)$, while sixty-seven participants (14.4\%) reported living alone. The mean $( \pm S D)$ number of years of experience/practice for participants was 12.36 ( \pm $8.47)$, the majority of participants $(n=393 ; 84.7 \%)$ were government employees and two hundred and ninety-six (63.8\%) participants were medical doctors.

The clinical characteristics of participants are represented in Table 2. Twenty-one (4.5\%) participants reported having been infected with COVID-19 at the time they completed the survey, while nearly one-quarter ( $\mathrm{n}$ $=107 ; 23.1 \%$ ) participants had a friend or loved one who had been infected with COVID-19. One hundred and 
Table 2: Clinical characteristics of participants.

\begin{tabular}{|c|c|c|}
\hline Variable & Frequency $(\mathrm{N}=464)$ & Percentage (\%) \\
\hline \multicolumn{3}{|l|}{ Have you been infected with COVID $19 ?$} \\
\hline Yes & 21 & 4.5 \\
\hline No & 443 & 95.5 \\
\hline \multicolumn{3}{|l|}{ Has a friend/loved one been infected with COVID $19 ?$} \\
\hline Yes & 107 & 23.1 \\
\hline No & 357 & 76.9 \\
\hline \multicolumn{3}{|l|}{ Close contact or managed a case(s) of COVID 19: } \\
\hline Yes & 101 & 21.8 \\
\hline No & 363 & 78.2 \\
\hline \multicolumn{3}{|l|}{ Do you work in any of the isolation centres: } \\
\hline Yes & 115 & 24.8 \\
\hline No & 349 & 75.2 \\
\hline \multicolumn{3}{|l|}{ Availability of personal protective equipment (PPE): } \\
\hline Available but not sufficient & 354 & 76.3 \\
\hline Available in sufficient amounts & 37 & 8.0 \\
\hline Not available at all & 73 & 15.7 \\
\hline \multicolumn{3}{|l|}{ Ever been diagnosed with a psychological illness: } \\
\hline Yes & 26 & 5.6 \\
\hline No & 438 & 94.4 \\
\hline \multicolumn{3}{|l|}{ Diagnosed with or receiving treatment for a chronic medical condition: } \\
\hline Yes & 139 & 30.0 \\
\hline No & 325 & 70.0 \\
\hline \multicolumn{3}{|l|}{ Specific diagnosis $(n=139)$ : } \\
\hline Allergic rhinitis/Asthma/PTB/COPD & 22 & 15.8 \\
\hline Cervical/Lumbar spondylosis & 6 & 4.3 \\
\hline Diabetes mellitus (DM) & 7 & 5.0 \\
\hline Hypertension (HTN) & 62 & 44.6 \\
\hline Peptic ulcer disease (PUD) & 9 & 6.5 \\
\hline $\begin{array}{l}\text { More than one diagnoses (E.g., HTN, DM, Asthma, PUD, Glaucoma, } \\
\text { Osteoporosis) }\end{array}$ & 17 & 12.3 \\
\hline $\begin{array}{l}\text { Other single diagnoses (Hepatitis B, Cancer, Thyroid dysfunction, } \\
\text { Seizure disorder) }\end{array}$ & 16 & 11.5 \\
\hline
\end{tabular}

SD: Standard Deviation

one $(21.8 \%)$ participants reported having been in close contact with or managed a case(s) of COVID-19 and up to 115 (24.8) participants were working at isolation centers for patients infected with COVID-19. Over twothirds ( $n=354 ; 76.3 \%$ ) of the participants reported that personal protective equipment's (PPE's) were available in their facilities but not sufficient. Twenty-six (5.6\%) participants had a history of a psychological illness, before COVID-19, while one hundred and thirty-nine participants reported having an underlying chronic medical condition. Of the 139 participants with an underlying chronic medical condition, sixty-two (44.6\%) participants were hypertensive.

\section{Prevalence of anxiety symptomatology}

The mean GAD score was 4.18 ( \pm 4.20 ). The overall prevalence of anxiety symptoms among doctors and nurses in Nigeria in this study was $39.9 \%(\approx 40 \%)$. Mild anxiety was reported in $27.8 \%$ of participants, while moderate anxiety accounted for $10.1 \%$ of cases and $1.9 \%$ had GAD-7 scores of 15 or greater, corresponding to severe levels of anxiety. In other words, up to $12 \%$ of the participants had a clinically significant range of anxiety with GAD-7 scores of 10 or greater, which corresponds to moderate and severe levels of anxiety. Specific rates differed amongst the study population, the overall rate of anxiety symptomatology among doctors was $23.7 \%$ ( $n$ $=110)$ and $16.2 \%$ among nurses $(n=75)$. Also, moderate to severe levels of anxiety were reported in $6.4 \%$ of doctors and $5.6 \%$ of nurses respectively.

\section{Correlates of anxiety symptomatology (Bivariate analysis)}

This study found that younger participants were 
Table 3: The relationship between GAD and socio-demographic/clinical characteristics of participants.

\begin{tabular}{|c|c|c|c|}
\hline \multirow[t]{2}{*}{ Variable } & \multicolumn{2}{|c|}{ GAD } & \multirow[t]{2}{*}{ Descriptive Statistic } \\
\hline & Yes & No & \\
\hline \multicolumn{3}{|l|}{ Gender } & $X^{2}=9.831, d f=1$ \\
\hline Male & $12(6.3)$ & $177(93.7)$ & $P=0.002$ \\
\hline Female & $44(16.0)$ & $231(84.0)$ & OR: 10.575 \\
\hline \multicolumn{3}{|l|}{ Occupation } & \multirow{3}{*}{$\begin{array}{l}X^{2}=2.881, d f=1 \\
P=0.09\end{array}$} \\
\hline Medical doctor & $30(10.1)$ & $266(89.9)$ & \\
\hline Nurse & $26(15.5)$ & $142(84.5)$ & \\
\hline \multicolumn{3}{|l|}{ Employer } & \multirow{3}{*}{$\begin{array}{l}X^{2}=0.007, d f=1 \\
P=0.94\end{array}$} \\
\hline Government & $47(12.0)$ & $346(88.0)$ & \\
\hline Private & $9(12.7)$ & $62(87.3)$ & \\
\hline \multicolumn{3}{|l|}{ Marital status } & \multirow{3}{*}{$\begin{array}{l}X^{2}=10.951, d f=1 \\
P=0.001 \\
\text { OR:: } 9.823\end{array}$} \\
\hline Single/separated/divorced/widowed & $23(21.1)$ & $86(78.9)$ & \\
\hline Married/cohabiting & $33(9.3)$ & $322(90.7)$ & \\
\hline \multicolumn{3}{|c|}{ Has a friend or loved one been infected with COVID-19? } & \multirow{3}{*}{$\begin{array}{l}X^{2}=4.240, d f=1 \\
P=0.04 \\
\text { OR: } 3.924\end{array}$} \\
\hline Yes & $19(17.8)$ & $88(82.2)$ & \\
\hline No & $37(10.4)$ & $320(89.6)$ & \\
\hline \multicolumn{3}{|c|}{ Have you been infected with COVID-19? } & \multirow{6}{*}{$\begin{array}{l}X^{2}=9.372, d f=1 \\
P=0.002 \\
\text { OR: } 6.906 \\
X^{2}=0.078, d f=1 \\
P=0.78\end{array}$} \\
\hline Yes & $7(33.3)$ & $14(66.7)$ & \\
\hline No & $49(11.1)$ & $394(88.9)$ & \\
\hline \multicolumn{3}{|c|}{ Have you been in close contact with or managed a case(s) of COVID-19? } & \\
\hline Yes & $13(12.9)$ & $88(87.1)$ & \\
\hline No & $43(11.8)$ & $320(88.2)$ & \\
\hline \multicolumn{3}{|c|}{ Do you work at any of the isolation centres? } & \multirow{3}{*}{$\begin{array}{l}X^{2}=1.639, d f=1 \\
P=0.20\end{array}$} \\
\hline Yes & $10(8.7)$ & $105(91.3)$ & \\
\hline No & $46(13.2)$ & $303(86.8)$ & \\
\hline \multicolumn{3}{|c|}{ Availability of personal protective equipment } & \multirow{3}{*}{$\begin{array}{l}X^{2}=3.010 \\
F E=2.807 \\
d f=2\end{array}$} \\
\hline Available but not sufficient & $40(11.3)$ & $314(88.7)$ & \\
\hline Available in sufficient amounts & $3(8.1)$ & $34(91.9)$ & \\
\hline Not available at all & $13(17.8)$ & $60(82.2)$ & $P=0.248^{\mathrm{FE}}$ \\
\hline \multicolumn{3}{|c|}{ Have an underlying chronic medical condition } & $X^{2}=0.058, d f=1$ \\
\hline Yes & $16(11.5)$ & $123(88.5)$ & \multirow[t]{2}{*}{$P=0.81$} \\
\hline No & $40(12.3)$ & $285(87.7)$ & \\
\hline \multicolumn{3}{|l|}{ Psychological illness before COVID 19} & $X^{2}=5.727, d f=1$ \\
\hline Yes & $7(26.9)$ & $19(73.1)$ & $P=0.02$ \\
\hline No & $49(11.2)$ & $389(88.8)$ & OR: 4.529 \\
\hline
\end{tabular}

$X^{2}$ : Chi Square; P: P value; df: Degree of Freedom; OR: Odds Ratio

significantly more likely to experience anxiety $(37.29 \pm$ 8.79 years), compared to older participants (40.20 \pm 8.40 years), $t_{(462)}=2.42, p=0.02$. In the same vein participants with fewer years of experience were significantly more likely to report anxiety (9.36 \pm 7.30 years), compared to participants with more years of experience (12.77 \pm 8.54 years), $t_{(462)}=2.85, p=0.005$.

The findings from Table 3 demonstrate that significant socio-demographic and clinical factors associated with anxiety symptomatology include: Being female, single/separated/widowed, and having contracted the
COVID-19 infection, having a friend or loved one who has contracted COVID-19 and having a lifetime history of a psychological illness.

Furthermore, participants who reported the following patterns of coping with the pressure, stress and anxiety that accompanied the pandemic were significantly less likely to report experiencing anxiety. These coping patterns include: Maintaining a healthy lifestyle (using healthy diets and exercises) and spending time with family and friends who they live with (if feasible). This is suggestive of possible protective coping styles during 
Table 4: The relationship between GAD and participants pattern of coping.

\begin{tabular}{|c|c|c|c|}
\hline \multirow[t]{2}{*}{ Variable } & \multicolumn{2}{|c|}{ GAD } & \multirow[t]{2}{*}{ Descriptive Statistics } \\
\hline & Yes & No & \\
\hline \multicolumn{3}{|c|}{ Maintaining a healthy lifestyle (diet, exercises) } & \multirow{3}{*}{$\begin{array}{l}X^{2}=9.846, d f=1 \\
P=0.002 \\
\text { OR: } 9.047\end{array}$} \\
\hline Yes & $3(9.2)$ & $307(90.8)$ & \\
\hline No & $25(19.8)$ & $101(80.2)$ & \\
\hline \multicolumn{3}{|c|}{ Spending time with loved ones whom you live with (if feasible) } & \multirow{3}{*}{$\begin{array}{l}X^{2}=10.875, d f=1 \\
P=0.001 \\
\text { OR: } 10.567\end{array}$} \\
\hline Yes & $23(8.1)$ & 261 (91.9) & \\
\hline No & $33(18.3)$ & $147(81.7)$ & \\
\hline \multicolumn{3}{|c|}{ Getting social support from colleagues } & \multirow{3}{*}{$\begin{array}{l}X^{2}=4.020, d f=1 \\
P=0.05\end{array}$} \\
\hline Yes & $17(18.1)$ & $77(81.9)$ & \\
\hline No & $39(10.5)$ & $331(89.5)$ & \\
\hline \multicolumn{3}{|c|}{ Internet use } & \multirow{3}{*}{$\begin{array}{l}X^{2}=0.281, d f=1 \\
P=0.60\end{array}$} \\
\hline Yes & $45(12.5)$ & $315(87.5)$ & \\
\hline No & $11(10.6)$ & $93(89.4)$ & \\
\hline \multicolumn{3}{|c|}{ Getting scientific updates on COVID-19 } & \multirow{3}{*}{$\begin{array}{l}X^{2}=0.46, d f=1 \\
P=0.83\end{array}$} \\
\hline Yes & $38(12.3)$ & $271(87.7)$ & \\
\hline No & $18(11.6)$ & $137(88.4)$ & \\
\hline \multicolumn{3}{|c|}{ Maintaining communication with loved ones who are faraway (phone calls, media chats) } & \multirow{3}{*}{$\begin{array}{l}X^{2}=0.899, d f=1 \\
P=0.34\end{array}$} \\
\hline Yes & $46(12.8)$ & $312(37.2)$ & \\
\hline No & $10(9.4)$ & $96(90.6)$ & \\
\hline \multicolumn{3}{|c|}{ Getting enough rest between work hours } & \multirow{3}{*}{$\begin{array}{l}X^{2}=1.571, d f=1 \\
P=0.21\end{array}$} \\
\hline Yes & $33(13.9)$ & $204(86.1)$ & \\
\hline No & $23(10.1)$ & $204(89.9)$ & \\
\hline \multicolumn{3}{|l|}{ Religion } & \multirow{3}{*}{$\begin{array}{l}X^{2}=0.225, d f=1 \\
P=0.64\end{array}$} \\
\hline Yes & $27(12.9)$ & $183(87.1)$ & \\
\hline No & $29(11.4)$ & $225(83.6)$ & \\
\hline \multicolumn{3}{|c|}{ Taking out the anxiety or stress on colleagues and loved ones } & \multirow{3}{*}{$\begin{array}{l}X^{2}=1.671, d f=1 \\
P=0.20\end{array}$} \\
\hline Yes & $10(17.2)$ & $48(82.8)$ & \\
\hline No & $46(11.3)$ & $360(88.7)$ & \\
\hline \multicolumn{3}{|c|}{ Use of alcohol } & \multirow{3}{*}{$\begin{array}{l}X^{2}=0.636, d f=1 \\
P=0.70^{F E}\end{array}$} \\
\hline Yes & $1(5.9)$ & $16(94.1)$ & \\
\hline No & $55(12.3)$ & $392(87.7)$ & \\
\hline \multicolumn{3}{|c|}{ Use of other psychoactive substances } & \multirow{3}{*}{$\begin{array}{l}X^{2}=0.300 \\
P=0.476^{F E}\end{array}$} \\
\hline Yes & $1(20.0)$ & $4(80.0)$ & \\
\hline No & $55(12.0)$ & $404(88.0)$ & \\
\hline
\end{tabular}

$\mathrm{X}^{2}$ : Chi Square; P: P value, df: Degree of Freedom; OR: Odds Ratio

distressing times (Table 4).

\section{Factors associated with anxiety symptomatology}

Logistic regression was performed to ascertain the effects of age, years of experience, gender, marital status, occupation, having a friend or loved one infected with COVID-19, having personally been infected with COVID-19, previous history of psychological illness, coping with healthy diets/exercise and spending time with relatives (if feasible) on the likelihood that participants have anxiety. The logistic regression model was statistically significant, $\chi^{2}(10)=56.711, p$ $<0.0001$. The model explained $22.1 \%$ (Nagelkerke $R^{2}$ ) of the variance in GAD and correctly classified $87.9 \%$ of cases. Females were approximately 4 times more likely to experience anxiety symptomatology than males. Fewer years of work experience was associated with an increased likelihood of experiencing anxiety. A previous history of psychological illness was significantly associated with an increased likelihood of experiencing anxiety. Furthermore, coping with healthy lifestyle modifications (diet and exercises), as well as spending time with family and friends (when feasible), were associated with a reduced likelihood of experiencing anxiety (Table 5).

\section{Discussion}

This study revealed that anxiety symptomatology 
Table 5: Logistic regression of factors associated with GAD.

\begin{tabular}{|l|l|l|l|l|l|l|l|}
\hline Variable & B & S. E & Wald & Df & AOR & 95\% Cl & P \\
\hline Age & -0.04 & 0.04 & 1.309 & 1 & 0.96 & $0.90-1.03$ & 0.25 \\
\hline Years of experience & 0.09 & 0.04 & 5.851 & 1 & 1.10 & $1.02-1.18$ & 0.02 \\
\hline Gender & 1.34 & 0.42 & 10.228 & 1 & 3.82 & $1.68-8.68$ & 0.001 \\
\hline Married/cohabiting & -0.70 & 0.35 & 4.025 & 1 & 0.50 & $0.25-0.98$ & 0.05 \\
\hline Occupation & 0.42 & 0.35 & 1.417 & 1 & 1.52 & $0.76-3.05$ & 0.23 \\
\hline $\begin{array}{l}\text { Has a friend/loved one been infected with } \\
\text { COVID-19 }\end{array}$ & 0.68 & 0.38 & 3.113 & 1 & 1.96 & $0.93-4.16$ & 0.08 \\
\hline Have you been infected with COVID-19 & 0.73 & 0.62 & 1.403 & 1 & 2.08 & $0.62-6.97$ \\
\hline Psychological illness & 1.19 & 0.53 & 4.947 & 1 & 3.28 & $1.15-9.34$ & 0.24 \\
\hline Healthy lifestyle (diet, exercises) & -0.71 & 0.33 & 4.786 & 1 & 0.49 & $0.20-0.93$ \\
\hline Spending time with loved ones & -0.75 & 0.33 & 5.298 & 1 & 0.48 & $0.25-0.89$ \\
\hline Constant & 0.89 & 1.35 & 0.427 & 1 & & 0.02 \\
\hline
\end{tabular}

B: Regression Coefficient; S.E: Standard Error of Regression Coefficient; Wald: Wald Chi Square; df: Degree of Freedom; OR: Odds Ratio; Cl: Confidence Interval; Bold figures in $p$-value column indicate statistically significant results at $p<0.05$

is common amongst doctors and nurses in Nigeria, during the ongoing COVID-19 pandemic. Generally, approximately $40 \%$ of participants reported experiencing anxiety, with varying levels of severity. Also, over a tenth of participants were diagnosed with moderate to severe levels of anxiety during the time of this research. Furthermore, participants of younger age, those with fewer years of work experience, participants who were single/separated/widowed, female participants, those who had contracted the COVID-19 infection, those who had a friend or loved one who had contracted COVID-19 and those who affirmed to a lifetime history of a psychological illness, were significantly more likely to report experiencing anxiety. On the contrary, participants who reported coping with the stress by maintaining a healthy lifestyle, and spending time with close relatives, were less likely to report experiencing anxiety. After controlling for other socio-demographic and clinical factors, multivariate analysis demonstrated that female gender, fewer years of work experience and a lifetime history of psychological illness, independently increased the risk of anxiety, while healthy lifestyle modifications and spending time with close relatives, independently reduced the risk of anxiety symptomatology.

The overall prevalence of anxiety in this study is similar to the rate obtained from HCPs in studies conducted in Nepal, where anxiety was reported in $41.9 \%$ of HCPs and China, where $44.6 \%$ of health workers were reported to have anxiety $[8,20]$. Young, et al. reported a rate of anxiety of 63\% among 1311 HCPs in the United States of America (GAD-7 score $\geq 5$ ) [21]. Kibret, et al. also reported an overall prevalence of anxiety among HCWs of in a Hospital in Ethiopia to be about 63\% (GAD-7 score $\geq 5$ ) [22]. However, lower rates of anxiety have been reported among HCPs; Alzaid, et al. reported, 33.3\% among 441 HCPs in Saudi Arabia [23], 25.5\% was reported in Fujian, China [24], and Zhu, et al. reported a much lower rate of $24.1 \%$ in Wuhan,
China [25]. Also, systematic reviews and meta-analysis have reported pooled prevalence rates of anxiety amongst HCPs during the COVID-19 pandemic between the ranges of 23.2 and $25.8 \%[11,13,26]$. These rates are comparable to the rates of anxiety reported by persons in the general population during the COVID-19 outbreak $[27,28]$. This calls for urgent and deliberate strives to promote the mental health of individuals in the course of catastrophes such as the current pandemic.

The ascertainment criteria for the diagnosis of anxiety disorders, the specific population of HCPs who participated in these studies, the study settings (singlecenter versus nationwide surveys), the nature of the work environment, the incidence of the COVID-19 infection at the time the studies were conducted and the underlying individual vulnerabilities, are some of the factors that may account for the differences in the prevalence rate of anxiety in these studies.

Our study also examined possible factors that were associated with the anxiety symptomatology, experienced by nurses and physicians in Nigeria during the COVID-19 pandemic. Similar to findings in this study, previous research has also reported, female gender $[8,23,25,29]$, younger medical staff, whom expectedly also had less work experience [30], being suspected or confirmed with COVID-19 infection [23,25], family or loved one's history of COVID-19 infection [22,23,25], and HCPs mental health history [20,21,25], are significant factors associated with anxiety disorders among HCPs during the COVID-19 pandemic. Also, nurses were more likely to report anxiety, although this did not reach statistical significance in our study, the finding is supported by other research $[13,26]$. These findings advocate the need for targeted mental health interventions for vulnerable populations among HCPs, such as women and persons with background mental health morbidity. On the other hand, conflicting reports were documented in other studies; for instance, 
Kibret, et al. reported that age greater than 30 years old, being married, presence of chronic illness, and lack of accessibility of PPEs were significantly associated with anxiety [22]. Lu, et al. also reported that the shortage of PPEs and working in the isolation ward significantly increased the risk of anxiety in HCPs [24]. Also, Zhu reported that years of working $>10$ years and concomitant chronic diseases were significant predictors of psychological stress [25]. These studies show that various factors are associated with the anxiety experienced by the HCPs during the COVID-19.

Remarkably, we identified a few significant protective coping factors against anxiety in HCPs, during demanding times such as has been conferred by this pandemic. These include; healthy lifestyle modifications (diet and exercises) and spending time with close relatives when feasible. Correspondingly, adapting to a healthy diet was associated with less stress in HCPs as reported in previous research [31]. These factors essentially suggest that holistic health promotion through healthy living as well as the need for close relationships and social support for vulnerable/high-risk populations such as HCPs.

\section{Strengths and Limitations}

Most studies evaluating mental health issues amongst HCPs during the COVID-19 pandemic focused on the assessment of mental health problems in HCPs, however, this research in addition to assessing for anxiety symptoms, also studied the pattern of coping of the participants and how this affects the odds of experiencing anxiety. Our findings should be interpreted with the understanding that this data was collected at the early phase of the pandemic in Nigeria, where the number of confirmed cases of COVID-19 were quite few amongst HCPs and the general population. Also, as identified by Zhou, et al. the workload is a very important factor associated with anxiety experienced by nurses and physicians during the current pandemic [32]. It would have facilitated a more robust discussion if this factor was assessed to determine its possible effect on anxiety symptoms in our study population.

\section{Conclusion}

Anxiety symptoms occur frequently among frontline HCPs during the ongoing COVID-19 pandemic. It is important to pay attention to the mental health of HCPs especially during demanding periods. We hope that our findings would inform the development of intervention strategies for HCPs by relevant stakeholders such as the government, management of healthcare institutions and mental health professionals. Additionally, we recommend that vulnerable populations among HCPs, such as females and persons with background mental health morbidities should receive adequate attention. A collaborative approach that employs proactive measures to prevent mental disorders in HCPs should be undertaken. This includes but is not limited to; promoting healthy coping strategies, encouraging an adequate support system (especially, family support), setting up early interventional services like psychological counselling and providing an enabling work environment.

\section{Funding}

The authors received no external funding for this work.

\section{Contribution of Authors}

All the authors have contributed adequately to the manuscript preparation and completion.

\section{References}

1. World Health Organization (WHO) Mental health and psychosocial considerations during the COVID-19 outbreak.

2. Coronavirus will change the world permanently. Here's how. Politico.

3. Shreffler J, Petrey J, Huecker M (2020) The impact of COVID-19 on healthcare worker wellness: A scoping review. West J Emerg Med 21: 1059-1066.

4. Sharma N (2020) Stigma: The other enemy India's overworked doctors face in the battle against Covid-19.

5. Tham KY, Tan YH, Loh OH, Tan WL, Ong MK, et al. (2005) Psychological morbidity among emergency department doctors and nurses after the SARS outbreak. Hong Kong $J$ Emerg Med 12: 215-223.

6. Wu P, Fang Y, Guan Z, Fan B, Kong J, et al. (2009) The psychological impact of the SARS epidemic on hospital employees in China: Exposure, risk perception, and altruistic acceptance of risk. Can J Psychiatry 54: 302-311.

7. Wong TW, Yau JK, Chan CL, Kwong RS, Ho SM, et al. (2005) The psychological impact of severe acute respiratory syndrome outbreak on healthcare workers in emergency departments and how they cope. Eur J Emerg Med 12: 1318.

8. Lai J, Ma S, Wang Y, Cai Z, Hu J, et al. (2020) Factors associated with mental health outcomes among health care workers exposed to coronavirus disease 2019. JAMA Netw Open 3: e203976.

9. Ng K, Poon BH, Puar THK, Quah JLS, Loh WJ, et al. (2020) COVID-19 and the risk to health care workers: A case report. Ann Intern Med 172: 766-767.

10. Benjamin YQT, Nicholas WSC, Grace KHL, Mingxue J, Yihui G, et al. (2020) Psychological impact of the COVID-19 pandemic on health care workers in Singapore. Ann Intern Med 1-3.

11. Salari N, Khazaie H, Hosseinian Far A, Khaledi Paveh B, Kazeminia M, et al. (2020) The prevalence of stress, anxiety and depression within front-line healthcare workers caring for COVID-19 patients: A systematic review and meta-regression. Hum Resour Health 18: 1-14.

12. Vizheh M, Qorbani M, Arzaghi SM, Muhidin S, Javanmard $Z$, et al. (2020) The mental health of healthcare workers in the COVID-19 pandemic: A systematic review. J Diabetes Metab Disord 19: 1967-1978.

13. Santabárbara J, Bueno NJ, Lipnicki DM, Olaya B, Pérez MM, et al. (2011) Prevalence of anxiety in health care 
professionals during the COVID-19 pandemic: A rapid systematic review (on published articles in Medline) with meta-analysis. PNBP 107: 110244.

14. Elkholy H, Tawfik F, Ibrahim I, El-din SW, Sabry M, et al. (2020) Mental health of frontline healthcare workers exposed to COVID-19 in Egypt: A call for action. Int J Soc Psychiatry 67: 522-531.

15. World Health Organization (WHO) The impact of COVID-19 on mental, neurological and substance use services.

16. Sharma SK, Mudgal SK, Thakur K, Gaur R (2019) How to calculate sample size for observational and experiential nursing research studies? Natl J Physiol Pharm Pharmacol 10: $1-8$

17. Spitzer RL, Kroenke K, Williams JBW, Löwe B (2006) A brief measure for assessing generalized anxiety disorder: The GAD-7. Arch Intern Med 166: 1092-1097.

18. World Health Organization (WHO) Coping with stress during the 2019-nCoV outbreak.

19. Harrison P, Cowen P, Burns T, Fazel M (2018) Shorter oxford textbook of psychiatry. ( $7^{\text {th }}$ edn), Oxford University Press, New York.

20. Khanal P, Devkota N, Dahal M, Paudel K, Joshi D (2020) Mental health impacts among health workers during COVID-19 in a low resource setting: A cross-sectional survey from Nepal. Global Health 16: 1-12.

21. Young KP, Kolcz DL, O'Sullivan DM, Ferrand J, Fried J, et al. (2021) Health care workers' mental health and quality of life during COVID-19: Results from a mid-pandemic, National survey. Psychiatr Serv 72: 2.

22. Kibret S, Teshome D, Fenta E, Hunie M, Tamire T (2020) Prevalence of anxiety towards COVID-19 and its associated factors among healthcare workers in a Hospital of Ethiopia. PLoS One 15: e0243022.

23. Alzaid EH, Alsaad SS, Alshakhis N, Albagshi D, Albesher $R$, et al. (2017) Prevalence of COVID-19 related anxiety among healthcare workers: A cross-sectional study. J Family Med Prim Care 9: 4904-4910.
24. Lu W, Wang H, Lin Y, Li L (2020) Psychological status of medical workforce during the COVID-19 pandemic: A cross-sectional study. Psychiatry Res 288: 112936.

25. Zhu Z, Xu S, Wang H, Liu Z, Wu J, et al. (2020) COVID-19 in Wuhan: Sociodemographic characteristics and hospital support measures associated with the immediate psychological impact on healthcare workers. E Clinical Medicine 24: 1-11.

26. Pappa S, Ntella V, Giannakas T, Giannakoulis VG, Papoutsi E, et al. (2020) Prevalence of depression, anxiety and insomnia among healthcare workers during the COVID-19 pandemic: A systematic review and meta-analysis. Brain Behav Immun 88: 901-907.

27. Santabárbara J, Lasheras I, Lipnicki DM, Bueno NJ, Perez MM, et al. (2020) Prevalence of anxiety in the COVID-19 pandemic: An updated meta-analysis of community-based studies. PNBP 109: 110207.

28. Salari N, Hosseinian Far A, Jalali R, Vaisi Raygani A, Rasoulpoor S, et al. (2020) Prevalence of stress, anxiety, depression among the general population during the COVID-19 pandemic: A systematic review and metaanalysis. Globalization and Health 16.

29. Dai Y, Hu G, Xiong H, Qu H, Yuan X (2020) Psychological impact of the coronavirus disease 2019 (COVID-19) outbreak on healthcare workers in China. medRxiv.

30. Liang Y, Chen M, Zheng X, Liu J (2020) Screening for Chinese medical staff mental health by SDS and SAS during the outbreak of COVID-19. J Psychosom Res 133: 110102.

31. Mo Y, Deng L, Zhang L, Lang Q, Liao C, et al. (2020) Work stress among Chinese nurses to support Wuhan in fighting against COVID-19 epidemic. J Nurs Manag 28: 1002-1009.

32. Zhou Y, Wang W, Sun Y, Qian W, Liu Z, et al. (2020) The prevalence and risk factors of psychological disturbances of frontline medical staff in china under the COVID-19 epidemic: Workload should be concerned. J Affect Disord 277: 510-514. 